\title{
La intolerancia a la leche de vaca es una causa más de constipación crónica en los niños
}

Intolerance of cow's milk and chronic constipation in children. Iacono G, Cavataio F, Montaldo G et al. N Engl J Med. 1998;339:1100-4.

\author{
Objetivo \\ Determinar si la alergia a la leche de vaca puede causar constipa- \\ ción y/o lesiones perianales.
}

\section{Diseño}

Estudio cruzado* doble ciego comparando leche de vaca y de soja.

Lugar

Clínica gastroenterológica pediátrica. Palermo, Italia.

\section{Pacientes}

Se incluyeron 65 niños derivados por sus pediatras por presentar constipación crónica (CC) refractaria al uso de laxantes. La edad promedio fue de 34.6 meses (rango:11- 72). Se definió CC como retención crónica de materia fecal con una defecación cada 3 a 15 días. Se excluyeron pacientes con constipación secundaria a causas conocidas.

\section{Intervención}

En la primera visita se realizó a todos los pacientes examen físico buscando lesiones anales, biopsia rectal, estudios cutáneos de alergia y laboratorio. Los pacientes fueron randomizados para recibir durante 15 días leche de vaca o de soja, continuando con una semana de dieta libre (período de lavado* psicológico). A continuación los pacientes se cruzaron para recibir el otro tipo de leche durante 15 días más.

Los pacientes que respondieron a la dieta con soja fueron sometidos luego de un mes sin lácteos a una prueba de provocación con leche de vaca o leche de soja en forma doble ciego.

\section{Medición de los resultados principales}

Los niños con 8 o más deposiciones durante un período de tratamiento (15 días) fueron considerados como respondedores.

\section{Resultados principales}

De los 65 pacientes, 44 mejoraron su catarsis mientras recibían le che de soja (respondedores: $68 \%$ ) y ninguno mientras recibía leche de vaca ( $p<0.001$ para cada uno de los períodos del estudio cruzado). La fisura anal y el dolor asociado a la defecación también se resolvió en los pacientes respondedores. Síntomas concomitantes de intolerancia a la leche de vaca (broncoespasmo, rinitis o dermatitis) fueron más comunes en los pacientes respondedores (11/44 vs. $1 / 21, p=0.05)$. En los respondedores hubo una mayor frecuencia de Ig E específica contra antígenos de la leche de vaca (18/44 vs. $2 / 21, p=0.009$ ). Los 44 pacientes que respondieron fueron luego sometidos al desafio con leche de vaca o leche de soja. Ninguno de los que recibieron leche de soja tuvo cambios clínicos. Todos los que recibieron leche de vaca presentaron constipación con heces duras y molestias al defecar luego de 5 a 10 días de dieta.

\section{Conclusiones}

La constipación crónica puede ser un síntoma de intolerancia a la leche de vaca. La biopsia rectal no mostró una alteración específica de la mucosa. La presencia concomitante de otros signos de intolerancia alimentaria (broncoespasmo, rinitis, dermatitis) y la resolución de las fisuras anales severas aumenta la probabilidad de que la constipación se deba a intolerancia a la leche vacuna.

\section{COMENTARIO}

La alergia a la leche de vaca puede manifestarse en el aparato digestivo desde la boca hasta el ano, siendo los síntomas más frecuentes el vómito, la diarrea y el dolor abdominal ${ }^{1}$. Las manifestaciones son en general transitorias; y ya a los dos o tres años de edad o aún antes se suele restablecer la tolerancia ${ }^{1}$. El desafío oral con el alimento en cuestión en estudios doble ciego y controlados con placebo es el test de referencia o gold stardard para diagnosticar alergias alimentarias². En este estudio se demuestra con bastante certeza (evidencia grado I) que la leche de vaca puede ser un agente etiológico en algunos chicos con constipación crónica. Una posible fuente de sesgo en este estudio es el potencial desenmascaramiento*, debido a que la leche de vaca y la de soja tienen un gusto y un aroma diferente pudiendo ser identificada tanto por los lactantes como por sus padres y sus médicos, si éstos huelen el biberón. De todos modos, es poco probable que este conocimiento influya en el hábito catártico de los niños.

La pregunta pendiente es con qué frecuencia la intolerancia a la leche de vaca causa constipación crónica ${ }^{3}$. Es muy probable que en este estudio la frecuencia de la intolerancia se haya sobrestimado como causa de constipación ya que: 1) los pediatras que derivaron los pacien-

tes conocen que el lugar del estudio se dedica a alergias alimentarias y pudieron haberlos preseleccionado; 2) los pacientes incorporados habían sido tratados con laxantes sin éxito. Por el tipo de diseño y tratándose de una población muy seleccionada, este estudio no puede responder esta pregunta y habrá que esperar estudios en atención primaria.

La retención fecal funcional es la causa más frecuente de constipación en la infancia ${ }^{4}$. En los niños con constipación que no han respondido al tratamiento con laxantes y dieta rica en fibras estaría indicado la prueba de eliminar la leche de vaca de la dieta ${ }^{3}$. Cabe aclarar que también se han descripto reacciones alérgicas gastrointestinales a la leche de soja y una gama de enfermedades similares a las que provoca la leche de vaca (enteropatía, enterocolitis y proctitis). ${ }^{5}$

Si la intención es prevenir, la leche materna sique siendo el alimento ideal para el niño. Lo protege de las alergias alimentarias de tres formas a) disminuye la cantidad de proteínas extrañas a la que está expuesto, b) induce una más temprana maduración de la barrera intestinal que impida la entrada de macromoléculas, y c) provee protección pasiva a través de la Ig A secretoria. ${ }^{1}$

\section{*Ver Glosario}

\section{Dr. Juan Pablo Mouesca}

Hospital de Niños R. Gutierrez.

\section{Referencias}

1. Rezzónico CA. Alergia alimentaria. En: Pediatría Meneghello. Meneghello J, Fanta E, Paris E y Puga T(Eds.) 5ºd. 1997: 1169-73.

2. Sampson H. Alergias alimentarias. En: Oski Pediatría. Principios y práctica. Oski FA, De Angelis CD, Feigin RD, Warshaw JB(Eds.). 1993: 221-5.

3. Loening-Baucke V. Constipation in children. NEJM 1998: 339:1155-6.

4. Abi-hanna A, Lake AM.Constipación y encopresis en la infancia.PIR (en español) 1998; 19: 66-74.

5. American Academy of Pediatrics. Committe on Nutrition. Soy protein-based formulas: Recommendations for use in infant feeding. Pediatrics 1998; 101: $148-153$. 